\title{
The Extent of Settling down Check Disputes through Arbitration in Jordanian.
}

\author{
${ }^{1}$ Dr. Farouq Ahmad Faleh Al azzam , ${ }^{2}$ Dr. Mohamad Al Shible \\ Jadara university. Jordan
}

\begin{abstract}
The check is a tool of fulfillment in the commercial law. The legislator has been subject to strict penalties. The check includes two parts, civil part and criminal part. In this research, we discussed the possibility of resorting to arbitration in settling down check disputes.

As a result, the criminal case falls or ends between the parties to the dispute after they agree to resolve the dispute between them except for a public right that cannot be waived. But in the same time no public rights exists it civil disputes, in the time that criminal protection for check in Jordan is coming as extra protection to the check because many reasons which the spread use of check as a credit tool is the most important.

The purpose of this research is to demonstrate the extent to which arbitration can be applied as a mean of settling down disputes in checks disputes, which are considered as commercial papers and to determine the extent to which this affects the criminal case.

This section has been dealt with in two parts: Section One, the possibility of arbitration in check disputes. In the second section, the effects of resorting to commercial arbitration, and we concluded that there is a possibility to resort to arbitration in checks disputes regarding the two forms of disputes that may be initiates, especially when we know that the Jordanian legislator was silent regarding this issue. Accordingly, it is recommended that specific legal provisions relates to arbitration be issued clarifying the possibility of using arbitration in check disputes because of its positive aspects in commercial disputes.
\end{abstract}

Keywords: Check, Criminal law, Commercial law, Commercial Transactions, settling down disputes, Arbitration.

\section{Introduction}

Check is considered one of the most prominent commercial papers in modern times, because of the role it plays in the embodiment of commercial speed, which has made it widely spread in the commercial circles, because it is considered a tool of fulfillment, and can not in any way be a tool of guarantee under penalty of punishment, Check with great emphasis in different laws.

Check is defined as: "A written editor in accordance with conditions mentioned in the law and includes an order issued by a person who is the drawer to another person who is a bank and the drawee is obliged to pay a third person or to his order or to the check holder - the beneficiary - a certain amount upon access.[1]"

The issue of the check under the study of commercial law raises specific problems because it includes two parts, a penal part and a rights part. Jordanian law and comparative laws penalized the penal part, especially the offense of issuing a check that does not have an existing and defunct payment [2]. The arbitration research is related to the dispute resolution in this matter in terms of the rights aspect, because the arbitration law does not prevent arbitration in commercial disputes in general, and there is nothing in the trade law that prevents arbitration and reconciliation. Moreover, arbitration is a style affect the criminal action.

Thus, the criminal action ends or falls between the two opposing parties or their agreement to waive and resolve the dispute between them. This is an exception to the general rule in the case of the public right, which is the property of all and may not be waived or reconciled [3]. Therefore, it can be said that the reconciliation between the drawer and the beneficiary of the check affects the criminal case. As for the

\footnotetext{
${ }^{1}$ Dr. Farouq Ahmad Faleh Al azzam, IJSRM Volume 06 Issue 06 July 2018 [www.ijsrm.in]

Page 6
} 
checks, the reconciliation takes place in which the criminal and legal action is dropped, because this is similar to discharge or fulfillment when the drawer pays the check amount at any stage in which the case was to be adjudicated, since the beneficiary does not require this consent.

But the most important problem in our research is the trade disputes and ways of solving them through resorting to alternative means to settle disputes around them. The most important alternative means is arbitration. Therefore, the purpose of this research is to demonstrate the extent and feasibility of the application of arbitration - as one of the means of settling commercial disputes - in the settlement of check disputes which are considered commercial papers and to which the provisions of the Commercial Law apply, also to determine its impact in the criminal case.

Arbitration disputes have a commercial nature, and arbitration as a means of resolving disputes is referred to commercial disputes. However, law, whether arbitration law or commercial law, did not provide the possibility of resorting to arbitration as a means of settling these disputes.

The importance of arbitration as a means of resolving the dispute is evident, because it is characterized by the achievement of speed. The arbitration process developed until the legislator joined the law by a special law. In Jordan, the Jordanian legislator also enacted a special law for arbitration, pointed in general to use arbitration in disputes with commercial nature leaving a general rule, but he did not specify the types and types of disputes that could be resorted to arbitration for settlement.

This is even more important when looking at the check as a commercial dispute, which is linked to a criminal offense or a criminal claim, so it is important to recognize the possibility of resorting to arbitration in resolving the dispute of checks and to indicate the impact on the criminal part of the case. It is also important that the parties to the dispute in the check dispute may not stop there. Some people may be affected by the trade paper or the effects of the trade paper may evade them, but they will not be involved in the trade dispute until a certain point. In terms of the extent to which these persons are affected by the use of arbitration to settle the dispute of checks to which they may be associated with the relationship of endorsement or collateral. Accordingly, we will divide the research into two parts: the first section deals with the possibility of resorting to arbitration in the dispute of checks, and in the second section: the effects of recourse to arbitration in checks.

\section{Section I: The Possibility of Arbitration Dispute Checks.}

To investigate the possibility of arbitration in disputes related to the check, we must investigate the possibility of arbitration in the check as a civil dispute in the first demand, and then show the pictures of the agreement to arbitrate the check in the second demand.

The first requirement: the possibility of arbitration in the check as a civil conflict.

In the beginning, arbitration is defined as an agreement to bring the dispute to a particular person or persons to separate it from the competent court.[4]"On conciliation in a check, there is nothing specifically provided for in return, nothing prevents it, The agreement on resorting to arbitration is a general matter, since the general rule is that arbitration may be in matters where it is permissible to settle, where the Jordanian Arbitration Law contains a general rule on its validity. The provisions of this law apply to any arbitration in Jordan, regardless of the nature of the legal relationship in which the dispute revolves, whether contractual or non-contractual.[5] On the other hand, arbitration may only be agreed upon by a natural or juridical person who has the right to dispose of his rights[6].

From this we conclude that arbitration may be agreed upon in the dispute concerning the check. This is confirmed by the fact that the check applies to commercial provisions in the Commercial Law. The Jordanian Trade Law states that if the provision of this law is not applied, the provisions of the Civil Code shall apply to commercial articles. The application of these provisions shall only be in accordance with the principles of the Commercial Law[7]. The origin of the law is that commercial law is applied in commercial matters unless it is provided for in the commercial law. Civil law applies to the extent that commensurate with the commercial provisions, in this regard, the following question is raised, which may be raised in this area, if this agreement closes the door of recourse to the civil judiciary to claim the value of the check as that protection has become related to the interest of the beneficiary and not the public interest, as long as the law allowed him to reconcile the check, Is still relevant to a peremptory norm in accordance with the traditional concept of public order, which considers all the rules of criminal law to be peremptory norms, which can not be agreed upon, and therefore can not be reconciled and where arbitration can not be agreed upon? With reference to the fact that the Jordanian law allowed the establishment of a personal right case according to

\footnotetext{
${ }^{1}$ Dr. Farouq Ahmad Faleh Al azzam, IJSRM Volume 06 Issue 07 July 2018 [www.ijsrm.in] Page 7
} 
the general right case before the judicial authority before which this lawsuit is brought, and it may be set up before the civil courts separately [8].

In the Jordanian Trade Law, if a criminal action is instituted against the drawer, the personal prosecutor may request the competent criminal court to adjudicate to him the amount of the value of the doubt without prejudice to his right if necessary in all the implications. The right holder may claim his rights before the ordinary courts if he so chooses [9].

In response to this, we find that the Egyptian Constitutional Court has taken the arbitration award in the check and violated the ruling issued by the General Federation of Chambers of Commerce and the Cairo and Alexandria Chambers. It dealt with the issue of arbitration in the check while resolving the dispute between two judgments, one of which was issued by an arbitral tribunal, The first was to obligate the beneficiary of the check to return to the drawer and the second to punish the drawer for a misdemeanor check without a balance, Where he confirmed the ruling on the permissibility of arbitration and that he drops the public right [10].

As to the extent to which arbitration may be agreed upon in the check, that is, the arbitration of the check as a civil dispute, the recourse of the beneficiary to the civil court in the case of an agreement between him and the drawer to arbitrate the disputes arising therefore poses no problem, And it is established that arbitration in disputes of a financial nature is not a problem. Therefore, the agreement of the drawer or the beneficiary to resort to arbitration in respect of civil disputes arising from the check leads to the closure of the civil road to the beneficiary whether the beneficiary resorts to this route in the form of a performance order or in the form of Obligation to bind [11].

However, there is a situation which may lead to some difficulties, namely, the case of the claim of civil rights by the beneficiary before the court, which examines the misdemeanor of the check without a balance. This claim is mainly for compensating the beneficiary for damages caused by the perpetrator of the crime of doubt without balance. If the arbitration agreement on disputes arising from the check terminates the right of the beneficiary to the civil prosecution before the criminal court, or is this claim one of the main requirements of the criminal case and the impact of the agreement on arbitration is applied to the criminal jurisdiction.

The answer to this by reference to the Code of Criminal [12] Procedure is that it enables the victim to commit himself to civil rights before the court before which the criminal proceedings are pending, in any case in which the case was pending until the decision to close the case was made. The civil claim here is the case filed by the person who suffered damage from the crime seeking compensation for such damage. As for the check, the legislator permitted the filing of the proceedings before the criminal court and before the civil judge in accordance with the criminal case [13].

\section{The Second Requirement: The Agreement on Arbitration In The Check}

The agreement on arbitration generally takes two forms [14]: either an arbitration clause in the contractual relationship between the parties, or an arbitration agreement (arbitration agreement) [15], and with respect to the forms of arbitration agreement in the check, The dispute may be settled independently or in a particular contract in respect of all or some disputes that may arise between the parties. The arbitration agreement may also be concluded after the dispute has arisen, even if a lawsuit has been filed in front of any judicial body. Shall be referred to arbitration in a precise manner or the agreement shall be null and void [16].

Therefore, the images are the agreement independent of the contract on which the checks were issued or on the basis of a clause of the base contract provided that the checks are stated in their numbers and values under the terms of this contract and that it can be done before or after the dispute arises, The same check, and here the effect of this condition applies to all parties and all signatories of the appearance and guarantors.

\section{Section II: Effects of Arbitration on Checks}

There are traces of resorting to arbitration in checks, we deal in two demands: the effect of the arbitration clause in the check on the criminal case in the first demand, and then the effect of arbitration agreement in terms of people in the second demand.

First Requirement: Effect of the Arbitration Clause in the Check on the Criminal Case

\footnotetext{
${ }^{1}$ Dr. Farouq Ahmad Faleh Al azzam, IJSRM Volume 06 Issue 07 July 2018 [www.ijsrm.in] Page 8
} 
In the beginning, reference must be made to the definition of arbitration, which is the final decision made by the arbitral tribunal on the subject matter of the dispute, whether this decision is comprehensive for all or part of the dispute. Whether the arbitral tribunal accepts or rejects all of the requests, the other part. In the dispute before the arbitral tribunal, one party may request certain requests that are rejected by the other in full and are filed on a counterclaim. After the exchange of regulations and memorandums and the submission of evidence, the Commission shall reserve the case for judgment and shall issue its final judgment in all the applications of the parties once. This is the final judgment [17]. The arbitration is based on two principles:

a. Consensual Principle: that the arbitration is based on a consensual basis in terms of recourse to it, and determine all that relates to the arbitration process of formation, law, procedures, jurisdiction, and implementation of the sentence, ie to any system can be subject to [18]. The forms of will and satisfaction in international commercial arbitration take the form of an arbitration agreement, an arbitration clause and a permanent arbitration agreement.

B. Compulsory principle: Any decision issued in the dispute submitted to the arbitration shall take the form of the judicial judgment, and it is binding on the parties to the dispute without their acceptance if it is issued within the assets and within what is agreed upon. It is also a final judgment that can not be challenged, except in very rare cases that will be discussed, often related to the request for review in the case of new facts or the state of interpretation.

As for the effect of the arbitration clause in the check on the criminal case, for civil law we apply the provisions of the arbitration law or arbitration agreement. In the case of conciliation, the criminal case is suspended and the execution of the penalty is suspended in the case of conciliation. There is nothing in the Jordanian arbitration law such as the Egyptian version No. 27 of 1994 that all that may lead to the completion of the criminal proceedings and the suspension of the sentence, In the event that the plaintiff is entitled to the criminal proceedings, the beneficiary may reconcile with respect to the value of the check [19].

This may be related to public order and the idea of rules of the penal system. However, in the penalty there is room for reconciliation, as the researcher pointed out, and there is nothing in the arbitration law that prevents arbitration because it is permissible to conciliate. This can be applied to the crime of the check without a balance. In which case it was decided that the conciliation leads to the expiry of the criminal case, it has made this case a sole right of the victim and the beneficiary, which we see with it that the agreement to arbitrate disputes arising from the check also closes the path of criminal justice, And the victim may not the beneficiary of the check to evaluate a misdemeanor check without balance, whether direct claim or by the public prosecutor. The agreement to submit all disputes of the check to the arbitration body means waiver of consent to resort to the judiciary, whether civil or criminal.

\section{The Second Requirement: The Effect of Arbitration Agreement in Terms of Persons}

The impact of an arbitration agreement will be examined in terms of persons, the researcher points out that the arbitration agreement requires writing, or it will be avoid. The arbitration agreement does not apply except to those who signed it and accepted it explicitly. In the field of check, the arbitration agreement does not take effect in the face of the drawer and the beneficiary, any problems, but the problem arises for the appearance of them and for the reserve guarantors.

\section{First: The Effect of Arbitration Agreement on Appearance:}

This varies depending on the type of endorsement and the types of endorsement intended here: the transfer of ownership, and Authorization [20].

a. Transfer of Ownership: the endorsement which transfers the ownership of the trade paper including the rights, with all the guarantees to the appearance thereof, unless it comes in a form intended or understood as intended to be the mortgage [21].

The researcher has shown previously that the arbitration requires writing for the agreement, and because the appearance of it (the site to him) in the endorsement of the transfer of ownership is considered by third parties in respect of the contract basis on which the arbitration was agreed and signed by the drawer and the beneficiary, the arbitration agreement does not apply to face it, As well as some other defenses, such as the principle of relative effect of the contract, and the rule of disqualification of defenses for the bearer of goodwill in the check as a commercial paper [22].

${ }^{1}$ Dr. Farouq Ahmad Faleh Al azzam, IJSRM Volume 06 Issue 07 July 2018 [www.ijsrm.in] Page 9 
B. Authorization (proxy endorsement): Is the signature on the back of the check by proxy to take the necessary measures to collect the value at maturity, which is to give the appearance of the receipt of the paper and take legal action when refraining from fulfilling the return of the signatories [23] This endorsement has the same effect as the Agency, and can only be confirmed by the Agency. It is not the owner of the right to the contents of the check, which affects the arbitration agreement.

As for the arbitration contract or the base contract, the appearance in the proxy endorsement (Authorization) is considered by third parties, but its legal status is different from the legal status of the appearance of it as a manifestation of ownership, because the latter exercises its right to the claim arising from the check in its original form, acting as an agent for appearance. If the proxy endorsement has been made to the appearance from another appearance (another site), it does not apply in the face of the arbitration clause because it does not apply mainly against this other appearance, but if the endorsement was made to him from the first beneficiary, the arbitration clause to which it applies In the face of the appearance of the proxy mechanism.

The insurance endorsement is not envisaged in the check because the check is due to performance as soon as it becomes available, and for the short period of time that the law requires it to be submitted [24] so this is outside the scope of our study.

\section{Second: Effect of the Arbitration Agreement for the Reserve Guarantors.}

It is natural to say that whoever signed the check as a reserve guarantor to fulfill its value. The arbitration clause was not included in the check itself, but in the basic contract [25] that included the mention of the check, the arbitration clause in this contract does not apply to him because he did not expressly consent to it basic contract ${ }^{1}$. Because the reserve guarantor is a guarantee whereby the guarantor undertakes to pay the guarantor of the bond in solidarity with the person to whom the guarantee was made. The guarantor's obligation shall be based on his signature. If such guarantor wishes to apply to the arbitration clause, he shall renounce his will by signing again the arbitration agreement or condition (the base contract).

\section{Conclusion:}

The research found that there is a possibility of resorting to arbitration in check disputes, in respect of the two forms of disputes that may be received on the check, as a commercial paper subject to the provisions of the Commercial Law, and that the disputes that arise are commercial in nature, for the check specifically.

This possibility was found when it was found that there is no provision for recourse to arbitration in Jordanian arbitration law or Jordanian commercial law, and in return there is nothing to prevent it, and the provisions of conciliation and agreement to resort to arbitration are public matters, The Arbitration Law stipulates that in the matters where it is permissible, the Jordanian Arbitration Law provides a general rule on its validity. The provisions of this law apply to any arbitration in the Kingdom. It concerns a civil or commercial dispute between parties of public law or private law, the legal relationship that spins ho here the conflict, dogmatic or non-dogmatic.

It was found that the Jordanian judiciary did not address this issue, but the Egyptian judiciary in rare and famous rule has had the opportunity to discuss this issue, where he settled on the possibility of resorting to arbitration to settle down checks disputes, a ruling issued by the Egyptian Constitutional Court.

It has also been shown that arbitration in its form may respond to the settlement of check disputes as a general rule, where there is nothing to prevent or determine, arbitration may therefore be sought through the arbitration clause in the contractual relationship between the parties or through an arbitration agreement or so-called arbitration partner

In this case, the penalty clause in case of conciliation is suspended and the execution of the penalty is suspended in the case of conciliation. There is nothing in the Jordanian arbitration law to confirm this. , Such as the Egyptian Arbitration Act No. 27 of 1994, which stated that all that may be settled leads to the expiry of the criminal proceedings and the suspension of the execution of the sentence, but this is considered to be one of the general rules of Jordanian law.

The effect of the arbitration agreement in terms of persons, both in terms of appearances, was found to be different, depending on the type of endorsement. As for the transfer of ownership, the appearance in this 
endorsement is considered by others to be the basis for the arbitration. The arbitration agreement is not applicable to countering it, along with some other defenses as a relative principle of the effect of the contract and the rule of clearing defenses for the goodwill holder in the check as a commercial paper. As for the proxy endorsement, which has the same effects as the agency, it is not the owner of the right check content, which affects the arbitration agreement. As for the arbitration contract or the base contract, the appearance in the proxy endorsement is considered to be from third parties. If the proxy endorsement has been made to the appearance from another appearance, the arbitration clause does not apply to it because it does not apply mainly in the face of this other aspect. To whom the first beneficiary has been granted, the arbitration clause to which he is bound shall apply in the face of the appearance to which he is the agent.

As for the third type of representation, which is the insurance endorsement in the check, it is inconceivable, because the check is due to performance as soon as it becomes available, and for the short period of time that the law requires it to be submitted, so this is out of the scope of our study.

Finally, with respect to the effect of the arbitration agreement for the reserve guarantors, it was found that whoever signed the check as a reserve guarantor to fulfill its value. The arbitration clause was not the same as the check itself, but in the basic contract that included the mention of the check, because he did not explicitly accept him, since he did not sign it and was not party to the foundation contract.

Accordingly, it was recommended that specific and clear legal provisions should be issued indicating the possibility of arbitration in check disputes because of its advantages in commercial disputes. It also will mitigate the number of cases before the courts, in addition to the main advantage of resorting to arbitration to settle down disputes.

\section{References}

[1] Article 123 of the Jordanian Trade Law No. 12 of 1966.

[2] Article 421 of the Jordanian Penal Code

[3] Mohamed Said Nimour, Explanation of the Jordanian Code of Criminal Procedure, Dar Al-Thaqafa for Publishing and Distribution, Amman, 2011, I 2, p. 285.

[4] Ahmed Abu Al-Wafa, Optional and Mandatory Arbitration, Knowledge Establishment, Alexandria, 1971, I 9, p.

[5] Article (3) of the Jordanian Arbitration Law.

[6] Article 9 of the Jordanian Arbitration Law.

[7] Article 2 of the Jordanian Trade Law.

[8] Article 6 of the Jordanian Code of Criminal Procedure.

[9] Article 278 of the Jordanian Trade Law.

[10] Ruling of the Supreme Constitutional Court issued in the case of the Court of Cassation under No. 8 of $22^{\text {nd }} \quad$ Conflicts issued on August 4, 2001: http://www.justicelawhome.com/vb/showthread.php?t=16997

[11] Reza Abdel-Hamid, 2004, Arbitration in the check in light of the provisions of the Trade Law No. 17 of 1999 , p.

[12] Article 52 Criminal Procedure Code. And Muhammad Nimur, op. Cit., P. 172.

[13] Mohamed Nimour, op. Cit., P. 287.

[14] Zahir Al-Najjar, International Commercial Arbitration: Comparative Study, University Thought House, Alexandria, 2010, 1, p. 50. And Fuad Muhammad Muhammad Ali, previous reference, pp. 276-277.

[15] Abdul Hadi Abbas and Jihad Hawash, Arbitration, Legal Library, Damascus, 1997, I 2, p. 368.

[16] Article 11 of the Jordanian Arbitration Law.

[17] Hamza Haddad, The Arbitration Ruling and the Conditions of its Health, Submitted Research: The Arbitration Course in Engineering and Construction Contracts and the Preparation of the Arbitrators in Damascus, (30/11 - 1/12/2008), Organization: Arab Arbitration Chamber for Structural Engineering Contracts, 2008, p. 
[18] Fouad Mohamed Mohamed Abu Taleb, International Arbitration in Foreign Investment Disputes in Accordance with the Provisions of Public International Law: Comparative Study, University Thought House, Alexandria, 2010, 1, 46.

[19] Reza Abdel-Hamid, op. Cit., P. 3.

[20] Fawzi Mohammed Sami, Explanation of Commercial Law, Commercial Papers, C2, House of Culture for Publishing and Distribution, Amman, 2007, I 1, p.

[21] Fawzi Mohammed Sami, op. Cit., P. 136.

[22] Reza Abdel-Hamid, previous reference, p.

[23] Fawzi Mohammed Sami, op. Cit., P. 152.

[24] Fawzi Mohammed Sami, op. Cit., P. 333.

[25] Reda Abdel-Hamid, op. Cit., P. 6.

[26] Fawzi Mohammed Sami, op. Cit., P. 195. 